\title{
Presentación
}

\section{¿PUEDE SER LA UNIVERSIDAD DE HOY LA DE MAÑANA?}

\author{
Francisco Martínez Sánchez (Universidad de Murcia-España)*
}

Quiero comenzar agradeciendo a la Universidad de Rosario y concretamente a su Revista de la Facultad de Humanidades y Artes, Escuela de Ciencias de la Educación, el honor que me otorgan de poder presentar el $\mathrm{n}^{\circ} 8$ de la misma y quiero personalizar este agradecimiento en su Directora Magister Susana Copertari quien ha sabido dirigir esta publicación con acierto editorial, gran nivel científico y actualidad temática. Mil gracias Directora por la oportunidad que me brinda de poder presentar su revista y con ella poder exponer a los lectores mis inquietudes sobre la Universidad hoy, problema que a todos preocupa, del que todos hablamos y del que, con vista al futuro inmediato, poco se hace.

Dejando a un lado los antecedentes de uno u otro tipo considero aquí el surgimiento de las universidades en la Edad Media, aparición consecuencia de la necesidad de organizar el conocimiento disponible, o al menos aceptado, en determinados ámbitos en ese momento y por otro lado, transmitirlo a las nuevas generaciones formando a profesionales en los diferentes campos.

Con la llustración las Universidades se desarrollan, ya no sólo como centros docentes, sino que crecen sensiblemente en el ámbito de la investigación. Esta unión es la que configura las actuales instituciones universitarias, primando una u otra en función del perfil y características concretas de cada una de ellas.

Como no puede ser de otra forma, la investigación, ha ido evolucionando, tanto en sus campos y temas de estudio, como en sus métodos de trabajo y en la proyección de ella.

La investigación ha ido unida a las demandas, corrientes y necesidades sociales de cada momento sin abandonar la investigación básica que da co-

* Doctor en Pedagogía. Maestro Nacional. Profesor Titular de la Universidad de Murcia. España. Presidente de EDUTEC. (Asociación internacional para el desarrollo de la Tecnología Educativa y nuevas tecnologías aplicadas a la educación). 
bertura al resto. Poco tiene que ver un investigador universitario de hoy con uno del XVIII.

Por lo que se refiere a la enseñanza es necesario reconocer que una parte importante de las bases de lo que hoy se enseña en estas aulas se fraguó en el Siglo de las Luces. El tiempo transcurrido ha hecho que, los contenidos que hoy llenan los currícula universitarios, se hayan enriquecido acumulando buena parte de lo que ha ido produciendo la comunidad científica universal, si bien en este punto habría que hacer una consideración.

En los últimos años, prácticamente desde la Segunda Guerra Mundial, ha venido desarrollándose en el mundo científico una modificación de lo que han sido los campos concretos y específicos del conocimiento. En estos años se ha abierto una forma diferente de entender estos ámbitos. El camino iniciado ha dado lugar a grandes avances que ya no pertenecen a un campo clásico concreto. Se ha avanzado y mucho por los espacios fronterizos entre aquellos. Aquellos espacios tradicionales se denominan ahora con un adjetivo, que normalmente proviene de otro campo, y eso cuando no ha surgido un nuevo término para definirlos. Esta transformación ha permitido un salto cualitativo que posiblemente no tenía igual desde la referida llustración.

Por otro lado, se ha producido lo que se ha dado en llamar "aceleración del proceso histórico", fruto de la coincidencia de determinados avances en distintos campos.

Estos dos cambios están dando lugar a una dinámica social que poco tiene que ver con la era del mundo del conocimiento y con el del mundo laboral, cuando se crean las Universidades.

Entre tanto la Universidad a lo largo de los siglos, ha ido creando una organización, no sólo de gestión, que le obliga a desarrollar sus funciones de una forma muy determinada y que, en ocasiones como es el momento actual, le puede suponer una rémora en su adecuación a la realidad surgida de lo dicho más arriba, tanto en lo que tiene que ver con los contenido como con la velocidad que hay que realizarla. Esa puede ser la razón última por la que en ocasiones, y concretamente en el campo de la Enseñanza, se repita que la Universidad está "en su nube" lejos de la realidad y de los intereses de las aulas.

Dicho todo lo anterior, quisiera centrarme, en esta ocasión, en la Universidad, en tanto y en cuanto centro de enseñanza, y precisamente en la enseñanza como tal.

Mientras que en algunos aspectos se ha ido cambiando, más o menos, acorde con los cambios existentes fuera de ella, en la enseñanza no parece que exista esa adecuación.

La enseñanza, con todos los matices que queramos introducir, es fundamentalmente un acto de comunicación y ello comporta modelos, contenidos, canales, métodos, etc. que han de estar acorde con el entorno temporal y social en el que la institución se ubica. 


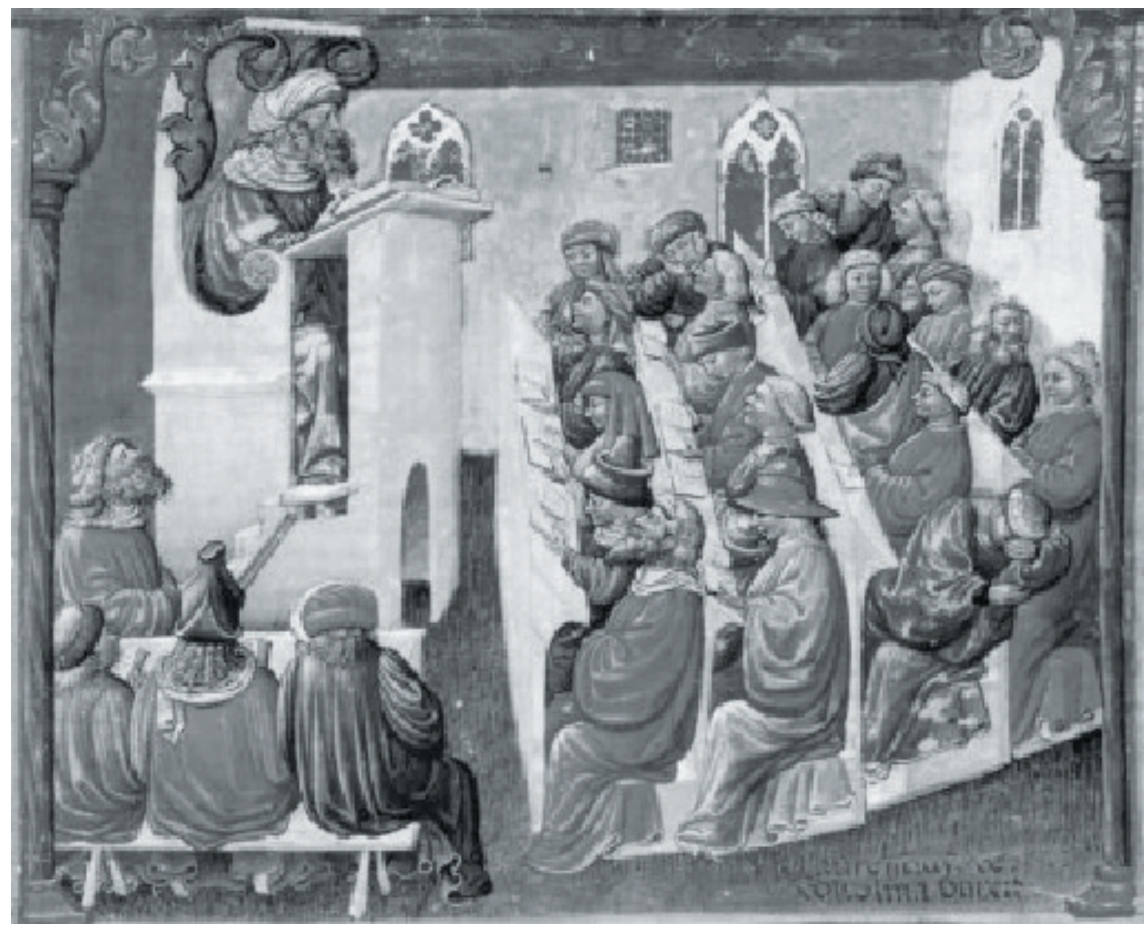

Incluyo una imagen de Henricus de Alemannia impartiendo clase en la Universidad de Bolonia pintado por Laurentius de Voltolina, del siglo XIV que me permite acometer mis reflexiones.

Observemos la situación de aula y la actitud de los alumnos.

Salvando las vestimentas podemos reconocer muchas de las conductas que hoy se dan en cualquier Universidad y en cualquier clase magistral. No ha cambiado mucho.

Si dejamos por un momento la enseñanza y miramos la oferta de contenidos, si bien se avanzó bastante, está muy lejos de las demandas que la sociedad tiene en la actualidad. La aceleración a la que me referí, llegó a la sociedad pero no a la Universidad, lo que supone un distanciamiento de la oferta con relación a los intereses y necesidades sociales, a los que la Universidad, teóricamente, debería dar respuesta.

Esta situación no es estática, se va acrecentando con el paso del tiempo, y está dando lugar al surgimiento de otro tipo de instituciones, que, con mayor agilidad, dan respuesta a las demandas reales, cuando no son las propias empresas quienes asumen la formación de sus trabajadores, sean estos del nivel que sean. 
Creo que buena parte del problema radica en la compleja organización, de todo tipo, que han creado estas instituciones, organización que hace lento y tedioso cualquier intento de modificación o de innovación de cualquier tipo.

La Universidad de los próximos años debe agilizar y facilitar la toma de decisiones, tanto en lo que tiene que ver con los currícula, como en la formación continua del profesorado. Crear unos estudios nuevos no puede requerir de un proceso de varios años ya que cuando venga a salir la primera promoción, posiblemente, no sea necesaria.

Centrándonos en la enseñanza como proceso de comunicación la Universidad no puede permanecer ajena a los cambios surgidos, las nuevas tecnologías de la comunicación, si bien están teniendo una cierta presencia en los centros, ésta es más fruto de la novedad mediática que de una transformación de las metodologías de trabajo de alumnos y profesores que es lo realmente significativo. Los métodos tradicionales se están viendo reforzados con estos novedosos, algunos ya no tan novedosos, medios.

Los nuevos modelos, apoyados por las tecnologías disponibles, deben basarse en la responsabilidad del alumno, quedando el profesor como guía o tutor, dejando de ser el responsable de todo el proceso de enseñanza-aprendizaje.

Podríamos pensar en cibercampus más que en tradicionales campus en los que venimos conviviendo desde la Edad Media.

Desde el punto de vista comunicativo los modelos emergentes deben basarse en que es el alumno quien diseña, construye su proceso de acceso a la información y decide su forma personal de aproximación al conocimiento, y por ello será el último responsable de su aprendizaje.

Evidentemente es necesario que sea capaz de asumir su responsabilidad consigo mismo, capacidad de organización, actitudes colaboracionistas, y algún criterio científico que le permita tomar decisiones.

Por su parte las instituciones precisan ser flexibles en los currícula, establecer criterios adecuados de colaboración interinstitucional, desarrollar sistemas de evaluación abiertos y autónomos de los currícula impartidos y una cierta predisposición a aceptar la "ruptura" de los espacios tradicionales ocupados por las materias que se imparten en ellas.

Estos cambios permitirán a la Universidad encajar en la realidad social a la que pretende servir, de lo contrario, es fácil pensar, que será superada por otras instituciones que sean capaces de responder con agilidad y nivel adecuado a las demandas reales de la sociedad en cada momento. 